\title{
Apontamentos de Matemática de Dom Ireneu Penna: construção de um impresso didático ${ }^{1}$
}

\section{The Apontamentos de Matemática by Dom Ireneu Penna: the construction of a didactic printed material}

\author{
Letícia Maria Ferreira da Costa de Morais $^{2}$ \\ Bruno Alves Dassie 3
}

\section{Resumo}

O objetivo deste texto é apresentar o processo de constituição do impresso didático Apontamentos de Matemática de Dom Ireneu Penna, destinado ao ginásio do Colégio de São Bento do Rio de Janeiro. Para isso, o texto é guiado pela rede de relações que o historiador Robert Darnton apresenta para a constituição de um livro. Após uma nota biográfica sobre o autor dos impressos, explica-se o contexto educacional da época em que eles surgiram - final da década de 1960, durante o Movimento da Matemática Moderna. Segue-se a análise do nascimento dos impressos, cujo surgimento deve-se à insatisfação do autor quanto aos manuais escolares disponíveis e a uma admiração pela coleção de livros didáticos do matemático belga Papy. A análise documental das fontes encontradas no acervo pessoal de Dom Ireneu, principalmente, leva-nos à conclusão de que a concepção dos Apontamentos é a imbricação de uma conjuntura educacional e política, de um encantamento e de uma influência intelectual de Papy, de uma questão relacionada aos editores e de uma existência de leitores/usuários.

Palavras-chave: História do livro didático, Movimento da Matemática Moderna, Dom Ireneu Penna, Papy.

\begin{abstract}
This paper presents the constitution process of the Apontamentos de Matemática, a didactic printed material written by Dom Ireneu Penna for the classes of Colégio de São Bento in Rio de Janeiro. The analysis is guided by the relations pointed by Darnton around the creation of a book. A biographical note about the autor of Apontamentos is followed by the explanation of the educational context where the material was produced, which is the 1960's, during the New Math Movement. On the sequence, the birth of the material is analyzed: it has been conceived after the dissatisfaction of the author about the didactic books available on the national market and his admiration on the Belgium didactic collection by Georges Papy. Documental analysis on the sources founded in Dom Ireneu's personal archive, mostly, lead us to the conclusion that the realization of the Apontamentos overlaps an educational and politic juncture, a glamour and an intellectual influence of Papy, a question related with the editors and the existence of readers/users.
\end{abstract}

Keywords: History of textbooks, New Math Movement, Dom Ireneu Penna, Papy.

Submetido em: 12/12/2018 - Aceito em: 29/03/2019 - Publicado em: 30/03/2019

${ }^{1}$ Este artigo é fruto de uma pesquisa de doutorado em andamento que visa construir uma versão da história dos Apontamentos de Matemática.

2 Doutoranda em Educação pela Pontifícia Universidade Católica do Rio de Janeiro. Email: leticia.hfc@gmail.com

3 Doutor em Educação pela Pontifícia Universidade Católica do Rio de Janeiro. Professor Associado da Universidade Federal Fluminense, Brasil. Email: badassie@ gmail.com. 


\section{Introdução}

Em 2016, a Companhia das Letras lançou uma edição crítica do livro Raízes do Brasil, de Sérgio Buarque de Holanda. Além de textos característicos de uma proposta dessa natureza, encontra-se, ao final do volume, uma série de reproduções de páginas da primeira edição de 1936, "pertencente ao autor e todo rabiscado com anotações, acréscimos e cortes destinados à composição do texto da segunda edição, que seria publicada em 1948" (Monteiro \& Schwarcz, 2016, p.486). Além de uma belíssima seleção de imagens, o que essas páginas nos revelam?

Em primeiro lugar, encontram-se registradas as marcas deixadas pelo leitor ${ }^{4}$. Este é um caso particular, mas não menos interessante, em relação à história da leitura, tendo em vista a dificuldade de localização deste tipo de registro. Darnton (2010, p.171), por exemplo, nos indica que

[...] há de ser possível desenvolver uma história, bem como uma teoria da reação do leitor. Possível, mas não fácil, pois os documentos raramente mostram os leitores em atividade, modelando o sentido partir dos textos, e os próprios documentos também são texto, o que requer interpretação. Poucos têm uma riqueza tal que possa fornecer um acesso, mesmo que indireto, aos elementos cognitivos e afetivos da leitura, e um ou outro caso excepcionalmente talvez não seja suficiente para se reconstruírem as dimensões internas dessa vivência. Mas os historiadores do livro já trouxeram à luz grandes quantidades de informações sobre a história externa da leitura.

Esse processo de "reação do leitor" também é um ponto importante quando se considera o autor como leitor de sua própria obra, como no caso citado anteriormente. Novamente, pode-se recorrer a Darnton, agora para relacionar as práticas de leitura com a constituição de um livro, segundo destaque que se pode citar a partir dos rascunhos de Sérgio Buarque de Holanda. Para Darnton (2010, p.125-126),

[...] de modo geral, os livros impressos passam aproximadamente pelo mesmo ciclo de vida. Este pode ser descrito como um circuito da comunicação que vai do autor ao editor (se não é o livreiro que assume esse papel), ao impressor, ao distribuidor, ao vendedor, e chega ao leitor. O leitor encerra o circuito [figura 1] porque ele influencia o autor tanto antes quanto depois do ato de composição. Os próprios autores são leitores. Lendo e se associando a outros leitores e escritores, eles formam noções de gênero, estilo, além de uma ideia geral do empreendimento literário, que afetam seus textos, quer estejam escrevendo sonetos shakespearianos ou instruções para mostrar um kit de rádio. Um escritor, em seu texto, pode responder a críticas a seu trabalho anterior ou antecipar reações que serão provocadas por esse texto. Ele se dirige a leitores implícitos e ouve a resposta de resenhistas explícitos. Assim o circuito percorre um ciclo completo. Ele transmite mensagens, transformando-as durante o percurso, conforme passam do pensamento para o texto, para a letra impressa e de novo para o pensamento. A história do livro se interessa por cada fase desse processo e pelo processo como um todo, em todas as suas variações no tempo e no espaço, e

\footnotetext{
${ }^{4}$ Um trabalho importante sobre análise de marcas de um leitor é: Amorim, B.D. \& Gomes, M.L.M. (2016). Possibilidades de compreensão das indicações metodológicas para o ensino de matemática na escola primária da primeira metade do século XX: estudo exploratório de uma obra da biblioteca pessoal de Alda Lodi. Anais do III ENAPHEM. (pp. 205-217). São Matheus, ES: Sociedade Brasileira de História da Matemática.
} 
em todas as suas relações com outros sistemas, econômico, social, político e cultural, no meio circundante. (Darnton, 2010, p. 125-126)

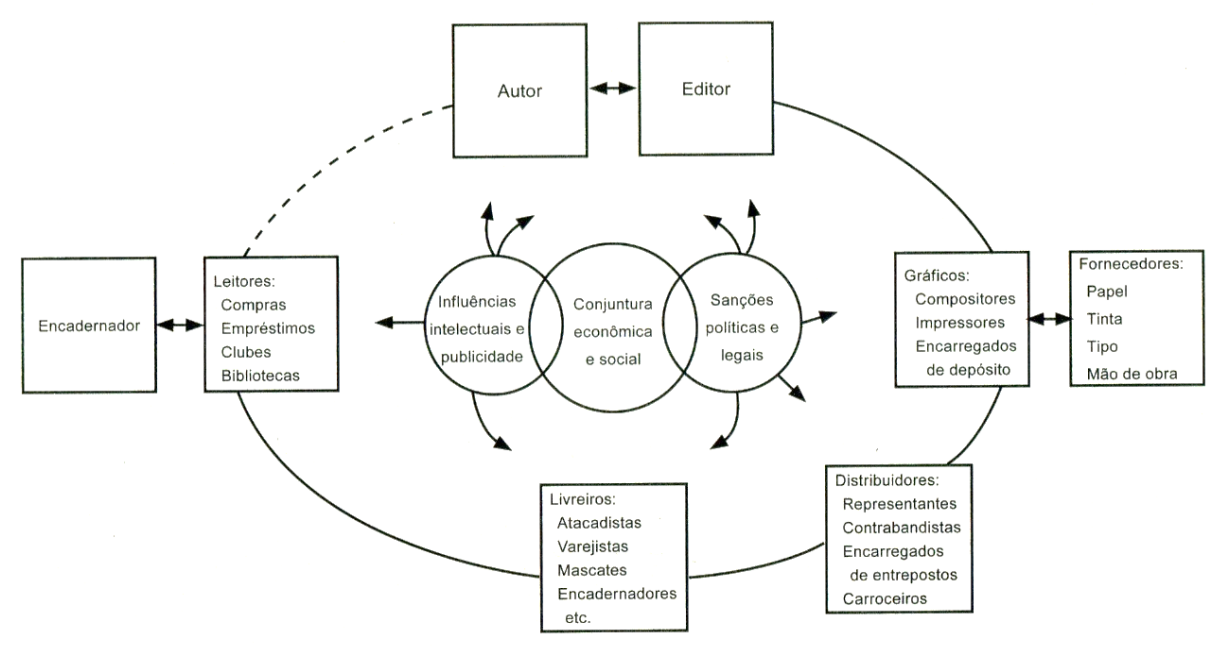

Figura 1 - Circuito de comunicação

Fonte: Darnton (2010, p.127)

A rede de relações que Darnton (2010) apresenta nesse circuito é bem complexa, porém, amplia as possibilidades de problematizações sobre as diferentes forças envolvidas na história do livro. Por outro lado, para compreender essa trama de condicionantes e pôr em funcionamento práticas historiográficas que busquem compreender a produção de livros didáticos ou material impresso utilizado pela escola, ainda se faz necessário assumir outros movimentos de análise.

Oliveira (2010) elabora uma síntese constituída a partir de uma proposta metodológica baseada na Hermenêutica de Profundidade que nos tem servido como aporte nas pesquisas sobre livros e impressos didáticos. Para Oliveira (2010), é necessário considerar duas vertentes na análise desse tipo de produção escolar: a formal e a contextual. Segundo ele,

$\mathrm{Na}$ vertente formal, que também temos chamado de interna, cabe ao pesquisador aprofundar-se na compreensão dos elementos (símbolos) que constituem a obra: capa, material, formatação, recursos gráficos, estruturação (capítulos, livros, parágrafos etc.), ordenação, encadeamento e apresentação dos conteúdos, proposta de abordagem didática - implícita e explicitada pelo autor - etc. Essa vertente não se resume, porém, à descrição dos elementos constitutivos da obra (embora a descrição seja uma etapa possível e importante nessa vertente), mas deve-se procurar interpretar o que esses elementos têm a nos "dizer". Na vertente contextual, que também temos chamado de sócio-histórica, incluem-se estudos [...] que possam contribuir para a compreensão de aspectos, aparentemente "externos" aos textos, referentes à época em que foram produzidos e/ou apropriados. [...] Estas vertentes, discriminadas por questões didáticas, não devem ser estanques. Ao contrário, o grande desafio da interpretação de textos didáticos é a articulação das compreensões elaboradas em ambas as vertentes. (Oliveira, 2010, p. 495).

Oliveira (2010) ainda nos apresenta uma lista de pressupostos assumidos a partir do trabalho com a Hermenêutica de Profundidade, dos quais destacamos o seguinte: “[...] a análise de livros didáticos é um processo de interpretação" (Oliveira, 2010, p.494). 


$$
* * *
$$

Mesmo que de maneira incipiente, os anúncios feitos até aqui já são suficientes para a apresentação da proposta deste texto e dos caminhos que foram percorridos para a elaboração de nossas interpretações sobre o processo de constituição de um impresso didático.

Os Apontamentos de Matemática, de Dom Ireneu Penna, formam um conjunto de quatro impressos didáticos destinados à sala de aula dos quatro anos do ciclo ginasial do Colégio de São Bento (CSB) da cidade do Rio de Janeiro. Foram produzidos por esse monge e professor de matemática no contexto do Movimento da Matemática Moderna (MMM), uma reforma internacional empreendida nas décadas de 1960 e 1970 no ensino de matemática.

O Movimento, que propunha novos conteúdos para a disciplina e modernas abordagens didáticas e metodológicas, apoiando-se nos mais recentes avanços da ciência matemática, suscitou a publicação de livros didáticos que atendessem às demandas da reforma. Os autores de manuais escolares de matemática, já consagrados nas instituições de ensino, também se viram na obrigação de reformular suas produções para atender às necessidades educacionais. Muitos livros de autores estrangeiros também foram trazidos para o Brasil e traduzidos ${ }^{5}$.

Entretanto, Dom Ireneu não estava satisfeito com os manuais existentes no mercado:

Dom Ireneu dizia explicitamente que, a julgar pelos compêndios que conhecia, a matemática moderna não vinha sendo bem ensinada no Brasil. Segundo ele o defeito essencial residia mais no como eram ensinados os conteúdos, e com qual ênfase eram abordados, do que nos conteúdos em si (Da Costa, 2014, p. 81).

Após algumas tentativas infrutíferas de ater-se a manuais publicados no Brasil, Dom Ireneu conheceu uma coleção de livros didáticos do matemático belga Georges Papy intitulada Mathématique Moderne. "Eu finalmente encontrei um sistema coerente", disse Dom Ireneu (apud Da Costa, 2014, p. 79).

Não havendo uma tradução para o português da coleção de Papy, Dom Ireneu resolveu adotar ao menos suas ideias, conteúdos, ordem de sua abordagem e metodologia de ensino, que era muito particular em Papy.

Foi desta forma que surgiram os Apontamentos de Matemática, baseados fortemente nos manuais de Papy, mas assinados por Dom Ireneu. A constituição dos Apontamentos é uma imbricação de uma conjuntura educacional e política - o MMM, de um encantamento e de uma influência intelectual de Papy, de uma questão relacionada aos editores - a falta de uma tradução, e de uma existência de leitores/usuários - os alunos e professores do CSB.

Os Apontamentos nunca chegaram a ser comercializados para o grande público. Sua

\footnotetext{
${ }^{5}$ Um exemplo é a coleção do School Mathematics Study Group, como pode ser visto em Silva, T. T. P. (2013) Os Movimentos da Matemática Moderna: compreensões e perspectivas a partir da análise da obra Matemática Curso Ginasial do SMSG. Mestrado em Educação Matemática. Universidade Estadual Paulista (UNESP). Retirado em 16 de agosto de 2018 de: http://hdl.handle.net/11449/91045.
} 
circulação foi restrita ao CSB e sua adoção pelos professores do ginásio manteve-se de 1967 a 2001, ano que Dom Ireneu faleceu.

Nossa proposta é, portanto, apresentar os movimentos de construção desse impresso didático. Consideramos como fonte de pesquisa principal o acervo pessoal de Dom Ireneu, conservado pelo Arquivo do Mosteiro de São Bento do Rio de Janeiro. O acervo de Dom Ireneu contém documentos que nos remetem às primeiras versões dos Apontamentos, manuscritas, além de outros documentos pessoais tais como cartas dirigidas a ele por editoras interessadas em traduzir os livros de Papy e documentos escolares, por exemplo, circulares aos pais sobre a adoção dos novos impressos, exemplares fotocopiados dos Apontamentos, rascunhos e versões mais antigas dos impressos. Contamos ainda com o acervo pessoal de um ex-aluno de Dom Ireneu, que usou as primeiras versões dos Apontamentos, em folhas avulsas e manuscritas, ainda em sua forma não encadernada ${ }^{6}$. Nesse acervo, encontram-se os cadernos do ex-aluno dos quatro anos ginasiais, além de folhas de exercícios, provas e partes dos Apontamentos ${ }^{7}$.

\section{O contexto de produção dos Apontamentos}

Abordaremos nesta seção o contexto de produção dos Apontamentos, iniciando com algumas palavras sobre o autor, seguidas pelo contexto político-educacional que o País, e em particular o Rio de Janeiro viviam à época de seu surgimento. Estaremos, assim, apontando e analisando duas das variáveis destacadas por Darnton (2010) na trama que envolve a produção de um livro.

\section{O autor - Dom Ireneu Penna}

Weimar Moreira Penna, como foi batizado Dom Ireneu ${ }^{8}$, nasceu em 1916 em São José dos Campos, no estado de São Paulo. Era filho de Alexandre Moreira Penna e neto do Conselheiro Affonso Augusto Moreira Penna, presidente do Brasil de 1906 a 1909. Veio para a capital ainda menino, fez seus estudos do ginásio e do secundário no Lycée Français do Rio de Janeiro, atual Colégio Franco Brasileiro, e diplomou-se em engenharia civil em 1937 pela Escola Politécnica do Rio de Janeiro. Trilhou um caminho, porém, mais voltado para a Educação do que para as ciências duras. Nos últimos anos de graduação em engenharia,

\footnotetext{
${ }^{6}$ O Arquivo Pessoal de Tiago Ferreira da Costa (APTFC) foi organizado pelos autores deste artigo em um projeto de Iniciação Científica, desenvolvido na Universidade Federal Fluminense.

${ }^{7} \mathrm{Na}$ historiografia do ensino de matemática e na historiografia da educação, percebemos Dom Ireneu e sua produção ainda pouco estudados. O que existe, até agora, é a dissertação de Da Costa (2014) que aborda algumas questões sobre esse professor e intelectual e destaca sua figura e seu trabalho. Dessa pesquisa, derivaram os seguintes artigos: Dom Ireneu Penna: intelectual, monge, professor e educador matemático (Dassie, Da Costa, 2014) e A trajetória de Dom Ireneu Penna e suas escolhas como educador matemático (Dassie, Da Costa, Carvalho, 2016).

${ }^{8}$ Quando um homem ingressa em um mosteiro beneditino, no dia da tomada de hábito, ele pode ter seu nome de batismo substituído por outro. Esse novo nome não tem, no entanto, efeito civil. É apenas uma nova denominação que simboliza a morte para o mundo e o nascimento para uma nova vida. Em nosso trabalho, usaremos tanto a denominação Weimar Penna quanto Dom Ireneu, ora referindo-nos a nosso protagonista em um momento anterior a sua entrada no mosteiro, ora já como monge.
} 
concluiu um curso de Licenciatura na Escola de Ciências da recém-fundada Universidade do Distrito Federal (UDF) para tornar-se professor secundário de Matemática.

Logo em seguida, ocupou alguns cargos na Secretaria de Educação e Cultura do Distrito Federal, primeiramente como oficial de gabinete, em seguida como professor adjunto de Didática da UDF e professor de matemática da escola técnica secundária. Em 1939, foi designado pelo prefeito do Distrito Federal, Henrique Dodsworth, para fazer estudos especiais do ensino de filosofia na Universidade de Paris (Sorbonne) e para analisar os sistemas escolares na França e na Inglaterra, pelo período de um ano (Da Costa, 2014).

Ressaltamos que as décadas de 1920 a 1940, no Brasil, foram períodos de transformações decisivas nos planos econômico, social (expansão das profissões de nível superior), político e cultural (criação de novos cursos superiores, expansão da rede de instituições culturais) e que, consequentemente, como aponta Miceli (2001, p. 117), esses períodos "se caracterizaram pela presença do engenheiro no domínio dos estudos sociais".

Podem, então, ser aplicadas a Weimar Penna - engenheiro, professor de matemática e de filosofia e possuidor de uma grande cultura clássica - as palavras de Miceli quando diz que nessas décadas, viam-se engenheiros que "dispunham de um mínimo de aptidões culturais para se lançarem em novas especializações do trabalho intelectual” (Miceli, 2001, p. 118).

Aluno do filósofo Jacques Maritain na França, Weimar Penna também seguiu seus ensinamentos no Centro Dom Vital, no Rio de Janeiro, órgão que congregava intelectuais da Igreja Católica9 ${ }^{9}$ A filosofia de base tomista, elucidada e difundida por Maritain e pelo Centro Dom Vital, foi para Weimar o parâmetro e a luz em todos os assuntos, inclusive para as questões relativas à educação.

Em 1941, Weimar ingressa na Abadia de Nossa Senhora de Montserrat do Mosteiro de São Bento, pertencente à ordem beneditina e instalada na cidade do Rio de Janeiro. Já como monge, tendo recebido o nome de Ireneu, ordenou-se sacerdote, e em 1947, entre as diversas funções que passou a acumular na Abadia, começou a dedicar-se ao colégio dirigido pelo mosteiro, o Colégio de São Bento (CSB), no qual permaneceu como professor de Matemática por 29 anos. No colégio, foi ainda professor de Religião, Desenho e Filosofia. No entanto, seu trabalho como educador matemático foi, sem dúvida, a parte mais importante de seu caminho como educador no CSB.

Dom Ireneu voltou a lecionar no ensino superior, acumulando mais essa função com a de coordenador de Matemática do curso ginasial do CSB. Foi professor na Faculdade São Bento, dirigida também pelo Mosteiro, onde lecionou filosofia e metafísica para muitas gerações de monges. Ainda, em 1957, Dom Ireneu foi convidado pela direção da Faculdade

\footnotetext{
${ }^{9}$ Fundado em 1922 por Jackson de Figueiredo, o Centro Dom Vital, juntamente com A Ordem, congregava os intelectuais católicos que se reuniam para assistirem ou ministrarem cursos, difundirem seu posicionamento acerca de inúmeras questões temporais, divulgarem questões de filosofia, sociologia e teologia.
} 
Nacional de Filosofia (FNFi) ${ }^{10}$, da antiga Universidade do Brasil, a lecionar Filosofia e Teoria do Conhecimento. Nessa instituição, permaneceu por onze anos, construindo sólidas relações de confiança e de respeito.

Em 1968, ao deixar a antiga Universidade do Brasil e recém-inaugurada Universidade Federal do Rio de Janeiro, Dom Ireneu ingressou na Universidade Santa Úrsula (USU), onde por cinco anos ensinou Fundamentos de Matemática I e II e Lógica Moderna. Nessa ocasião, pôde experimentar um pouco com seus alunos de graduação os métodos de ensino de matemática encontrados na produção didática de Georges Papy, a coleção de livros Mathématique Moderne, conhecidos por ele um ano antes.

Dom Ireneu permaneceu como professor do Colégio de São Bento até 1976. Sua atuação nessa instituição foi de tal modo expressiva, duradoura e respeitada que, mesmo aí não sendo mais um professor ativo, os Apontamentos de Matemática, suas ideias, métodos e indicações para o ensino de matemática permaneceram em vigor até 2001 (Da Costa, 2014).

\section{Contexto educacional e o ensino de matemática}

Os Apontamentos de Matemática foram produzidos nos primórdios da reforma no ensino de matemática ocorrida no Brasil e no mundo, que recebeu o nome de Movimento da Matemática Moderna (MMM).

Desde a década de 1950, matemáticos e professores de matemática, impulsionados por organizações internacionais como OEEC (Organisation for European Economic Cooperation) e UNESCO (Organização das Nações Unidas para a Educação, a Ciência e a Cultura) uniram esforços para trazer melhorias ao ensino de matemática, considerado obsoleto e inadequado às novas exigências políticas e econômicas de um mundo pós-guerra. Particularmente, visavam diminuir as lacunas existentes entre a matemática dos últimos anos escolares e a matemática superior. Desejava-se levar à escola uma matemática moderna, a matemática da época, com a recente visão estruturalista defendida pelo grupo Bourbaki.

Basicamente, um grupo de matemáticos franceses reunidos sob o nome de Bourbaki discutia uma matemática a partir do uso e do desenvolvimento de estruturas-mãe. Bourbaki identificou três "estruturas-mães": as estruturas algébricas, as estruturas de ordem e as estruturas topológicas. Defendia-se, assim, que era possível construir e desenvolver toda a matemática sobre a base única de algumas "estruturas-mães" fundamentais e suas combinações.

Essas estruturas, no entender desses matemáticos, eram ferramentas que economizavam pensamentos. Era necessário, então, modernizar o ensino de matemática considerando esse novo ferramental e essa nova visão sobre a disciplina.

\footnotetext{
${ }^{10}$ A Faculdade Nacional de Filosofia, nascida em 1939, foi extinta em 1968, quando a Universidade do Brasil já se transformara em Universidade Federal do Rio de Janeiro, o que ocorreu em 1965.
} 
Inicialmente na Europa (sobretudo França e Bélgica) e nos Estados Unidos, e posteriormente em todo o mundo, todos queriam "pôr em dia" o ensino tradicional das escolas e acrescentar aos programas determinados temas entendidos como sendo de matemática moderna: o estudo dos conjuntos; os conceitos algébricos de grupo, anel e corpo; o estudo dos espaços vetoriais; o estudo das matrizes; o estudo da álgebra de Boole; as noções de cálculo diferencial e integral e estatística. Essas noções e as "estruturas-mães" não constavam dos currículos escolares antes da reforma.

Era consenso também entre os professores que urgia a necessidade de modernizar os métodos de ensino. Não apenas novos conteúdos seriam necessários nas escolas, mas também o modo de os ensinar e abordar. Ou seja, a própria formação dos professores também estava em jogo durante o MMM.

Como é natural, a reforma adquiriu diferentes "caras" de acordo com as políticas e culturas de cada país. Era um movimento difuso e multifacetado, porém guiado basicamente por duas vertentes: a europeia e a americana.

Enquanto que na França a reforma visava introduzir a visão bourbakista na matemática escolar, nos Estados unidos a reforma significava, em primeiro lugar, elevar o baixo nível dos professores secundários de matemática e o baixo número de admissões de estudantes em cursos superiores de matemática, incluindo os de matemática aplicada e os de engenharia.

De Bock e Vampanenel (2015) comentam a diferença entre as duas correntes nos seguintes termos:

Na França, a demanda pela modernização veio das universidades e visava a introdução da moderna "Matemática de Bourbaki" na escola secundária. Nos Estados Unidos, a renovação da educação matemática era impulsionada pela indústria e pela política e buscava a modernização dos métodos de ensino. Consequentemente, a reforma americana foi considerada, em termos de conteúdos matemáticos "modernos", mais moderada do que a proposta francesa e mais voltada para a melhoria da qualidade de educação dos professores (p. 166 - 167, tradução nossa).

O MMM suscitou, mundialmente, a eclosão de materiais didáticos e livros-texto adaptados aos novos moldes preconizados de ensino de matemática. Houve, em nosso país, tanto a importação de diferentes modelos educacionais e de livros estrangeiros como a produção nacional de materiais didáticos. Esse movimento ainda promoveu congressos educacionais que tratavam especificamente, de modo pioneiro, do tema ensino de matemática moderna e acabaram trazendo para o Brasil referências do MMM em escala mundial, como Georges Papy (Bélgica) e Marshall Stone (EUA) (Soares, 2001).

As escolas do País, de modo mais ou menos sistematizado e consciente, tiveram seus currículos de matemática modificados e, muitas vezes, a metodologia de ensino adaptada, em especial pelo livro didático. A promoção do movimento no Brasil, em larga escala, se deu principalmente pelos cursos oferecidos aos professores e pelas publicações de centros de estudos que se formaram desde o início da década de 1960. O pioneirismo desses centros 
deve-se ao Grupo de Estudos em Educação Matemática de São Paulo (GEEM). Fundado em outubro de 1961 por um grupo de professores do estado de São Paulo, tendo como principal representante Osvaldo Sangiorgi, tinha por objetivo principal preparar os professores para a matemática moderna.

O GEEM teve uma força expressiva na divulgação do Movimento no Brasil, tanto pelos cursos que ofereceu por todo o País, como também pela coleção de livros Matemática curso moderno, de autoria de Sangiorgi, que seguia sua proposta de Assuntos Mínimos para um Moderno Programa de Matemática para o ginásio e para o colégio.

Valente (2008, p. 601) destaca que o grupo, ao apresentar os Assuntos Mínimos, mostrou-se muito forte e pioneiro ao definir um programa de matemática para o Brasil.

O sucesso e aprovação do trabalho do GEEM, liderado por Osvaldo Sangiorgi, na apresentação da nova proposta de modernização do ensino de matemática faz com que, na primeira publicação do Grupo, em finais de 1962, patrocinada pelo IBECC e pela Editora Universitária da Universidade de São Paulo, tenha na Introdução aos "assuntos mínimos" os seguintes dizeres: "O GEEM de São Paulo, apresentando ao IV Congresso Brasileiro do Ensino de Matemática a contribuição de sua equipe acerca do atual problema da modernização do ensino da Matemática no curso médio, almejou ir ao encontro do que é possibilitado pela Lei de Diretrizes e Bases da Educação Nacional, na certeza de que [...]surgirão reais diretrizes para um verdadeiro norte do ensino da Matemática nas escolas secundárias do país".

O GEEM incentivou a criação de novos grupos de estudos, em outros estados. Podemos citar, como exemplo, o GEEMPA (Grupo de Estudos sobre o Ensino da Matemática), em Porto Alegre, e o GEMEG (Grupo de Estudos de Matemática do Estado da Guanabara), no estado da Guanabara, ambos fundados em 1970.

As influências no Brasil para um novo ensino de matemática foram diversas, vindas principalmente dos Estados Unidos e da Europa. O GEEM, por exemplo, fundado por Sangiorgi, que esteve em cursos e estágios nos Estados Unidos, definiu-se como um grupo que espelhava seu semelhante americano, o School Mathematics Study Group (SMSG), no qual a preocupação maior era repensar o método de ensino ${ }^{11}$. Já o GEEMPA, em Porto Alegre, identificou-se mais com as propostas individuais do matemático e educador Zoltan Dienes (do Canadá), que concentrava seus interesses na metodologia, e pensava no uso de materiais manipuláveis para tornar os conceitos matemáticos mais concretos ${ }^{12}$. O GEMEG,

\footnotetext{
${ }^{11}$ Esse grupo foi desativado no final da década de 1970.

12 O GEEMPA foi criado em 1970 com a ideia inicial de atualizar os professores relativamente aos avanços e materiais didáticos do movimento da matemática moderna. Atualmente transformou-se em uma organização não governamental (ONG); manteve suas iniciais GEEMPA mas mudou seu significado. Hoje ele é o Grupo de Estudos sobre Educação, Metodologia da Pesquisa e Ação.
} 
na Guanabara, procurava seguir a metodologia de ensino de Georges Papy, que acreditava fortemente na introdução precoce da $\operatorname{abstração~}^{13}$.

Apesar de diversos ecos do movimento internacional da matemática moderna terem chegado ao Brasil, predominou a vertente norte-americana da reforma. Da Costa (2014) ressalta que

sobressaiu-se, no Brasil, a influência norte-americana do MMM. O GEEM, criado na cidade 7 de São Paulo em 1961 sob os moldes do grupo norte-americano SMSG, foi o principal veículo das ideias inovadoras do MMM no Brasil. Suas publicações serviam de modelo para muitos outros estados do país, inclusive para o estado do Rio de Janeiro. Tanto os princípios educacionais como a concepção de educação matemática, a própria finalidade desta disciplina e os conteúdos e didáticas propostos pelos Estados Unidos por meio do SMSG foram absorvidos e adaptados no Brasil. Ao contrário, a influência europeia não teve muito, ou quase nenhum, espaço ou força no País (p. 7).

Experiências que enfatizavam e seguiam modelos europeus foram pontuais (Soares, 2001). No Rio de Janeiro, em particular, sabe-se de três instituições de ensino que fizeram um trabalho institucionalizado baseando-se nas propostas de ensino de matemática de Georges Papy: o Colégio de São Bento, com Dom Ireneu Penna; o Centro Educacional de Niterói (CEN), com Arago Backx ${ }^{14}$; e o Colégio Estadual André Maurois, com as professoras Estela Kaufman Fainguelernt e Amélia Maria Noronha Pessoa de Queiróz.

Foi nesse contexto de revolução e modernização do ensino de matemática que surgiram os Apontamentos de Matemática, uma alternativa à matemática tradicional e uma solução para Dom Ireneu, que vivia insatisfeito com os materiais didáticos de matemática moderna disponíveis. Buscou incessantemente um livro adequado, até que se deparou com a coleção Mathématique Moderne de Papy, que lhe trouxe muita satisfação:

A diferença mais chocante no confronto com os programas correntes reside em que o programa [que é o seguido nos manuais de Papy] conduz a uma exploração mais profunda das noções de conjunto, relação [...], transformações do plano ... ao passo que o programa convencional tem uma pressa excessiva em abordar os "números" e as "operações", falhando desde o início no projeto de um pensamento matemático verdadeiramente novo (Penna, 1968, p. 1).

As propostas de Papy inspiravam-se na ideia de edifício lógico pensada pelos matemáticos profissionais da época, em especial pelo grupo Bourbaki. O trabalho do

13 O GEMEG era presidido por Arago Backx, que havia estagiado no Centre Belge de Pédagogie des Mathématiques, com Papy. Por falta de apoio da comunidade matemática e por falta de recursos, acabou encerrando suas atividades, dando lugar ao GEPEM (Grupo de Estudos e Pesquisas em Educação Matemática, fundado em 1976.

14 Arago de Carvalho Backx foi professor na Universidade Federal Fluminense e no Centro Educacional de Niterói, no Rio de Janeiro. Nessa escola, após um período de estudos no Centre Belge de Pédagogie de Mathématique, Backx iniciou um projeto no qual utilizou os livros da coleção Mathématique Moderne de Papy. 
matemático e professor belga foi arquitetar, de maneira acessível a crianças a partir de 11-12 anos, o que ele chamava de "Maison de la Mathématique" ou edifício da matemática. Sua base era a teoria dos conjuntos. Um de seus pilares principais, a reconstrução do corpo ordenado dos números reais e dos espaços vetoriais:

Este edifício da matemática, embasado pela teoria dos conjuntos, compreendia o estudo do grupo aditivo dos vetores, o corpo dos números reais, a estrutura de espaço vetorial (inicialmente estudado sem a definição de produto escalar) e a geometria plana. Os estudos culminavam com a estrutura de espaço vetorial euclidiano plano (nome específico que Papy adotava ao introduzir o produto escalar). Este é em grandes linhas o programa de construção do edifício para o antigo ensino ginasial [...]. Papy mostra-se consciente de que "trata-se de uma exposição ingênua e descritiva" destes assuntos, mas que, no entanto, "é apresentada de tal maneira que estudos posteriores mais profundos não exigem nenhum recondicionamento fundamental" [explica Papy]. Haverá apenas um aprofundamento dos conteúdos, mas nunca uma destruição ou não aproveitamento do que foi visto anteriormente (Da Costa, 2014, p. 27).

Satisfeito com essa visão da matemática como um edifício, e com o modo de construílo, Dom Ireneu decidiu adotar o modelo já solidificado e experimentado na Bélgica ${ }^{15}$. Para isso, foi necessário produzir os Apontamentos de Matemática, que são fundamentalmente quatro "apostilas de conteúdo" elaboradas para servirem de base às aulas de matemática dos quatro anos do ginásio no CSB. Esses textos didáticos, redigidos com o apoio da coleção de livros Mathématique Moderne de Papy, representaram o principal material utilizado para as aulas de matemática dos anos finais do ensino fundamental no CSB de 1968 até 2001.

A principal objeção de Dom Ireneu quanto aos manuais existentes residia no como era abordada a matemática moderna mais do que em quais conteúdos eram abordados. Papy também se preocupava muito com esse aspecto:

O modo como esta matemática moderna seria ensinada, o enfoque que se daria a cada um dos tópicos abordados, importava muito para G. Papy. Queria ele que todo o decorrer do aprendizado do aluno contribuísse para que este participasse ativamente na construção do que ele chamava de edifício da matemática; e isto deveria ser feito [segundo Papy] “a partir de situações simples e familiares” (DA COSTA, 2014, p. 27)

Papy possuía uma metodologia bastante singular, inventada por ele, que muito agradou a Dom Ireneu, que viu no autor um trabalho sério, que buscava formar e utilizar a intuição do aluno, tanto quanto desenvolver seu raciocínio. A linguagem das cordas e a linguagem das flechas são alguns exemplos dos meios pedagógicos por ele inventados. Notase, nessas metodologias, a importante função que as cores desempenhavam para Papy.

\footnotetext{
${ }^{15}$ A obra de Papy é resultado de cinco anos de ensino em turmas de um programa experimental. O conteúdo apresentado no livro já havia sido integralmente ensinado e experimentado com crianças de 12 a 13 anos, após inúmeras modificações e reavaliações oriundas de tentativas infrutuosas.
} 


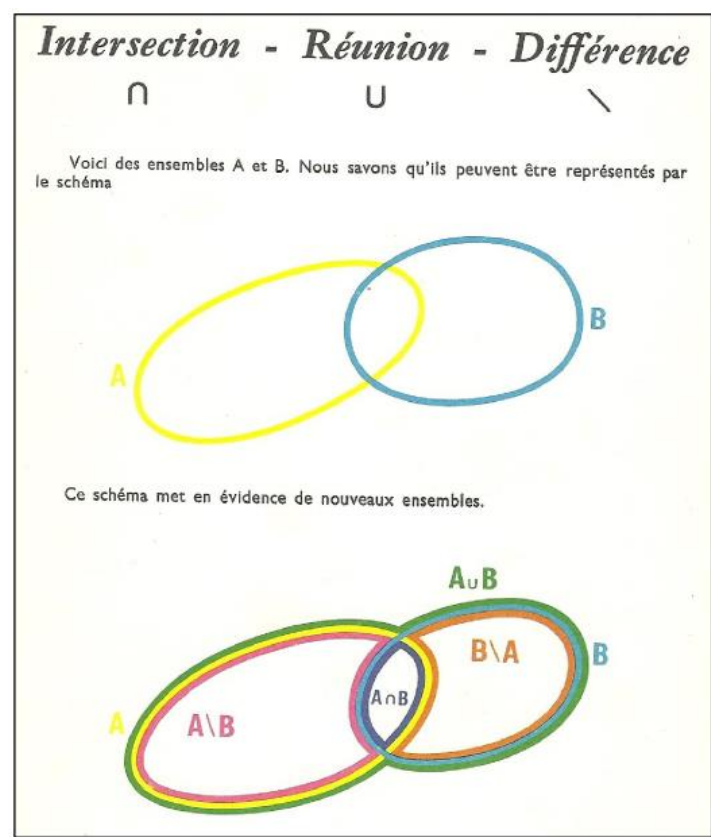

Figura 1 - Os subconjuntos obtidos a partir da Interseção, União e Diferença entre conjuntos apresentados por meio da linguagem das cordas.

Fonte: Papy, G. 1968, p. 27.

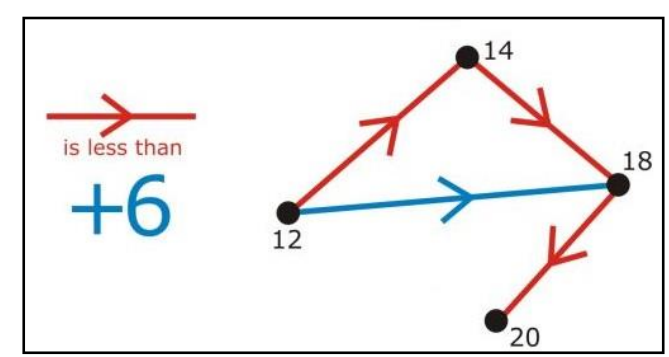

Figura 2 - Um papygrama - Uma relação entre os números realizada por meio das flechas. A flecha azul indica a relação " +6 ” e a flecha vermelha indica a relação "é menor que".

Fonte: Da Costa, 2014, p. 34.

Dom Ireneu decidiu adotar as propostas de Papy, consciente das dificuldades que daí adviriam: "Na verdade, não era nossa intenção inicial enveredar por esses caminhos, quanto mais não fosse pelo maior trabalho que daí nos adviria" (Penna, [1967 - 1970]).

A escolha do CSB pela modernidade constante nos métodos desenvolvidos por Papy tem um caráter singular quando comparada às mudanças ocorridas nas demais instituições de ensino brasileiras, em sua generalidade: o CSB não adotou a perspectiva americana do MMM e optou por seguir a europeia, nos moldes de Papy. Um segundo elemento que afirma a singularidade do ocorrido no CSB é a permanência dos novos conteúdos e metodologias no ensino de matemática do colégio. Estes, aos moldes de Papy, lá vigoraram por quase três decênios, mesmo após o MMM ter perdido seu vigor e influência nas escolas e estas terem abandonado os métodos "modernos" (Soares, 2001).

Os Apontamentos de Matemática são por nós percebidos não apenas como uma tradução da coleção de Papy, mas como obra singular e significativa de Dom Ireneu, uma reação a um momento da educação matemática, como um trabalho resultante de um arcabouço intelectual acumulado durante sua trajetória e de um conjunto de ideias e de ideais filosóficos e educacionais. 


\section{O nascimento de um impresso didático}

Pode-se dizer que os Apontamentos de Matemática de Dom Ireneu foram gestados durante seus longos anos de estudo da matemática - Dom Ireneu mantinha em sua sala diversos livros de matemática, nacionais e estrangeiros, e aplicava-se constantemente ao estudo - e durante seus anos de experiência nas salas de aula do CSB que conheceram sua constante insatisfação com o ensino da matemática. Dom Ireneu "era um educador completamente inconformado com o ensino de sua disciplina" e isso o fazia expor-se sempre ao diferente, muito antes de conhecer e seguir Papy (Da Costa, 2014, p. 79).

No momento em que chegou às escolas o MMM, e junto com ele os manuais escolares acrescidos de alguns novos conteúdos, metodologias e orientações para a disciplina, Dom Ireneu permaneceu inconformado. Sua reclamação fundava-se sobretudo no fato de que a álgebra e a geometria eram apresentadas como duas coisas divorciadas, não tendo um assunto a ver com o outro. Dom Ireneu inconformava-se ainda com a falta de coerência entre os diversos assuntos e com o modo como os alunos eram introduzidos à ciência:

Como a totalidade de manuais brasileiros disponíveis começou a introduzir os novos métodos e conceitos, sem, porém, alterar substancialmente a ordem das matérias e pontos tradicionalmente abordados, à medida que íamos expondo os conceitos fundamentais de Matemática pelos novos métodos, a própria necessidade de coerência nos foi distanciando desses manuais, obrigando-nos a fornecer aos alunos textos mimeografados das lições de exercícios (Penna, [1967 - 1970]).

Esse trecho de uma carta escrita por Dom Ireneu aos pais do CSB nos sugere que antes mesmo de se produzirem os Apontamentos, Dom Ireneu já exercia um papel de "autor", filtrando, escrevendo, produzindo textos e exercícios para os alunos. Muitos destes "textos mimeografados das lições de exercícios" podem ser encontrados em seu acervo.

A ideia de utilizar o Papy nas classes do ginásio do CSB chegou em 1967, quando Dom Ireneu teve contato com os livros do matemático belga. Conta o professor José Paulo Carneiro - também professor de matemática do CSB na época do MMM - que Dom Ireneu sempre lhe mostrava novos livros, pois encontrava nesse companheiro o mesmo entusiasmo por uma matemática mais coerente e bem-feita:

Dom Ireneu sempre me mostrava livros - e tem outros [de] que eu não me lembro o nome... Até o dia em que exatamente ele me trouxe o Papy. - Vou te mostrar uma coisa, ele disse. Aí ele me mostrou [o Papy] e eu fiquei encantado! Eu fiquei encantadíssimo com o Papy. [...] A essência do Papy era exatamente essa mistura constante, essa mescla constante entre geometria e o resto da matemática. Ele acabou com esse negócio de separar a geometria. Desde o início então ele vai fazendo geometria, e vai fazendo uma geometria axiomática correta. Obviamente Dom Ireneu ficou encantado com isso e chegou pra mim - lembro disso lá na sala dos professores do São Bento - e me disse assim: - Se eu agora formar as turmas por aqui - porque eu finalmente encontrei um sistema coerente - você aguenta eles lá no fim [nos três anos de científico]?" (Carneiro, 2012 apud Da Costa, 2014, p. 79 - grifos nossos).

Havia uma preocupação de Dom Ireneu quanto à preparação dos alunos nos últimos anos do secundário. À resposta afirmativa de Carneiro, responsável por esse último 
segmento, Dom Ireneu iniciou o processo de mudança de currículo para a matemática do ginásio. Isto significou o início de muito trabalho: formação dos demais professores nos novos moldes de ensino - conteúdo e metodologia - e, sobretudo, produção de material apostilas de conteúdo e exercícios.

Já no ano de 1967 foram adotadas, ainda que "timidamente", as ideias de Papy (Penna, 1969). Iniciou-se, então, no CSB, a produção de um novo material para as aulas de matemática. Não havendo um livro-texto, era necessário "produzir" as aulas, o que deu origem aos quatro volumes dos Apontamentos de Matemática. Ainda restam vestígios, nos acervos de Dom Ireneu e no acervo do ex-aluno, de capítulos avulsos dos Apontamentos, uns manuscritos, outros datilografados.

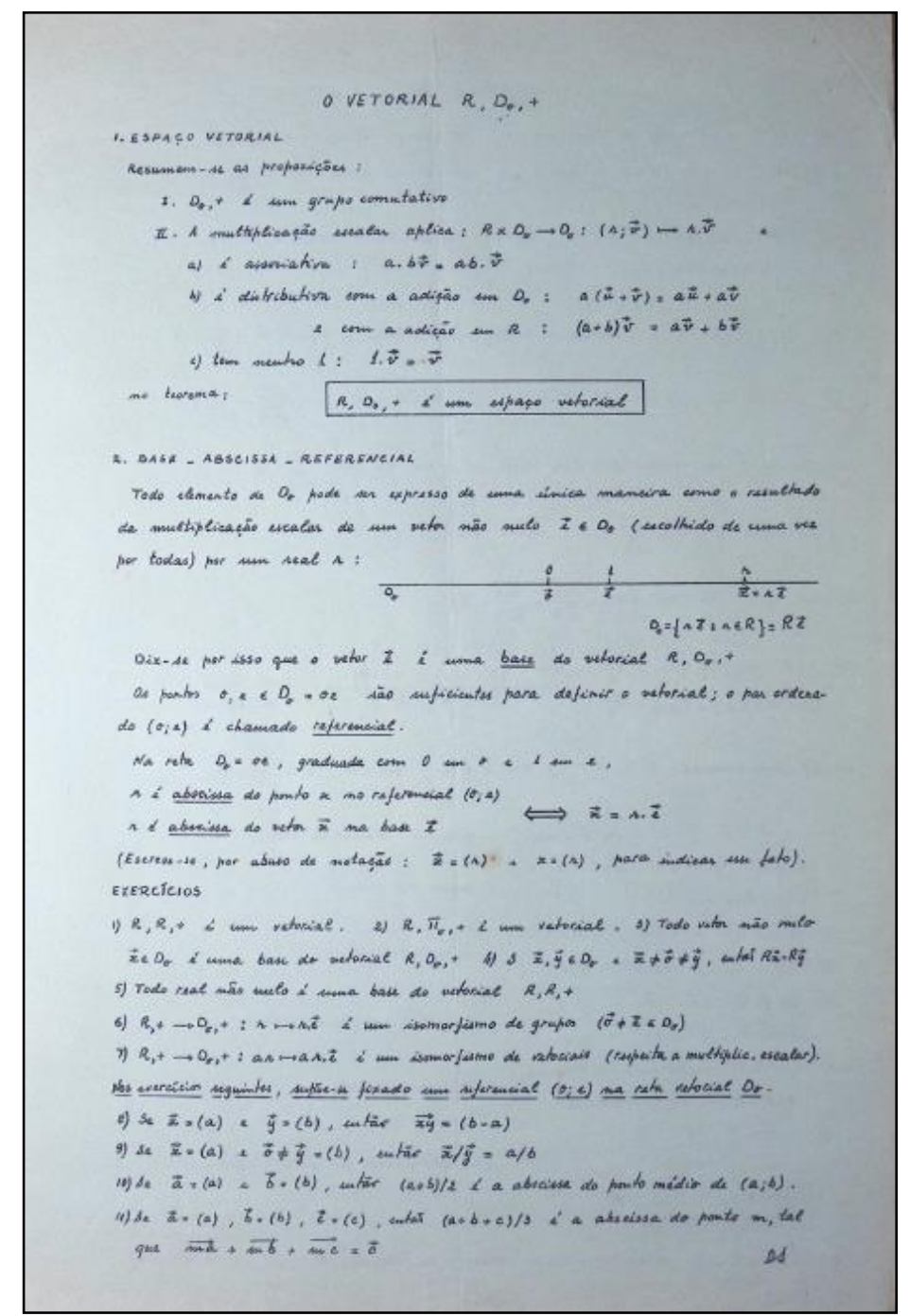

Figura 3 - Página manuscrita dos futuros Apontamentos de Matemática. Ao final, à direita, a rubrica de Dom Ireneu: DI.

Fonte: APTFC, Série 3, p.1.

Um fato importante na história dos Apontamentos é que o impresso poderia não ter existido. Em 1969, Dom Ireneu recebeu um pedido da Editora ao Livro Técnico para uma 
"tradução e adaptação do livro Mathématique Moderne livro I [MM1], de Papy" (Ao Livro Técnico, 1969, p. 1). O volume 1 de Papy seria dividido em dois tomos, 1 e 2 . No acervo de Dom Ireneu encontram-se documentos relativos a este trabalho, dentro os quais destacamos o convite da editora dirigido ao monge, especificando o prazo de entrega da tradução, o Manual do tradutor contendo as normas que deveriam ser seguidas por Dom Ireneu e o recibo de pagamento assinado por Dom Ireneu e pela secretária da editora. Dessas fontes conclui-se que a tradução foi acabada dentro do prazo e que Dom Ireneu foi pago por seu trabalho; no entanto, a editora nunca o publicou. Até o momento não temos fontes que esclareçam essa situação.

Entre os documentos relacionados a essa tradução encontra-se uma Apresentação, escrita por Dom Ireneu, como introdução de seu trabalho. Esse documento é muito rico em detalhes tanto sobre a tradução e adaptação do livro Mathématique Moderne quanto sobre os primeiros anos de experiência do papysmo no CSB. Esses detalhes, como veremos, compõem movimentos da produção de nosso objeto, os Apontamentos de Matemática.

Sobre a tradução, diz Dom Ireneu:

Digamos agora algumas palavras a respeito de nossa tradução. Procuramos fazê-la o mais literal possível, com um mínimo de adaptação. [...] Quanto à divisão do primeiro volume em dois tomos, salvo melhor aviso, pareceu-nos recomendável, pois dificilmente se poderia em um só ano esgotar a matéria do MM1 com real aproveitamento dos alunos. Corresponde isso à nossa experiência didática, em três anos sucessivos, com turmas de $1^{\text {a }}$ série que não tiveram um curso primário moderno, como é ainda regra entre nós. [...] O segundo tomo poderá ser estudado na $2^{\mathrm{a}}$ série e a maior parte, senão todo o $2^{\circ}$ volume (da coleção de Papy), na $3^{\mathrm{a}}$ série, ficando o $3^{\circ}$ volume para a $4^{\mathrm{a}}$ série ginasial (Penna, 1969, p. 1 -4).

Percebemos, daí, que Dom Ireneu, já com uma experiência de três anos baseando-se nos livros de Papy, propõe uma divisão para o curso ginasial, no qual seriam utilizados os 3 primeiros volumes da coleção Mathématique Moderne para os 4 anos ginasiais. A divisão proposta por Dom Ireneu foi mantida na divisão dos Apontamentos de Matemática em 4 volumes, conforme retratada no quadro a seguir: 
DOI: https://doi.org/10.20396/zet.v27i0.8654231

Quadro 1: Comparativo entre os Apontamentos e os livros de Papy

\begin{tabular}{|c|c|c|c|}
\hline & $\begin{array}{c}\text { Capítulos de } \\
\text { Apontamentos de Matemática } \\
\text { de Dom Ireneu }\end{array}$ & $\begin{array}{c}\text { Capítulos de } \\
\text { Mathématique Moderne } \\
\text { de Georges Papy }\end{array}$ & \\
\hline \multirow{14}{*}{ 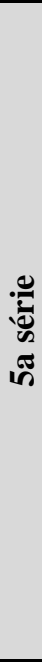 } & Cap I - Conjuntos - Primeiras noções & Cap 1 - Ensembles & \multirow{14}{*}{ 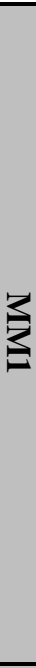 } \\
\hline & Cap II - Conjuntos - Inclusão & Cap 2 - Parties & \\
\hline & Cap III - Álgebra dos Conjuntos & $\begin{array}{l}\text { Cap } 3 \text { - Intersection - Réunion-Différence } \\
\text { Cap } 4 \text { - Algèbre des Ensembles }\end{array}$ & \\
\hline & Cap IV - Partição de um conjunto & Cap 5 - Partitions & \\
\hline & Cap V - Geometria & Cap 6 - Premiers éléments de géométrie & \\
\hline & Cap VI - Relações (1) & Cap 7 ( $1^{\mathrm{a}}$ metade $)$ - Relations & \\
\hline & Cap VII - Relações (2) & Cap $7\left(2^{\mathrm{a}}\right.$ metade $)$ - Relations & \\
\hline & Cap VIII - Relações (3) (Composição) & Cap 9 -Composition de relations & \\
\hline & Cap IX - Relações (4) (Ordens) & Cap 11- Ordres & \\
\hline & Cap X - Relações (5) (Funções) & Cap 12 - Fonctions & \\
\hline & Cap XI - O grupo das permutações & Cap 13 - Permutations & \\
\hline & Cap XII - Transformações do plano & Cap 14 - Transformations du plan & \\
\hline & Cap XIII - Projeções paralelas e ordem & Cap 15 - Projections parallèles et ordre & \\
\hline & Cap IV - Cardinais & Cap 16 - Cardinaux & \\
\hline \multirow{9}{*}{ 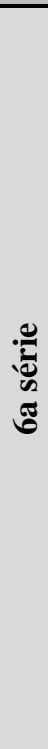 } & Cap I - Adição de Cardinais & Cap 17 - Addition & \multirow{7}{*}{3} \\
\hline & Cap II - Multiplicação de Cardinais & Cap 18 (parte) - Multiplication & \\
\hline & Cap III - Divisibilidade & Cap 18 (parte) - Multiplication & \\
\hline & Cap IV - O sistema binário de numeração & Cap 19 - Le système de numérationbinaire & \\
\hline & Cap V - Os inteiros Racionais & Cap 20 - Les entiers rationnels & \\
\hline & $\begin{array}{l}\text { Cap VI - Equipolências - Translações - } \\
\text { Vetor }\end{array}$ & $\begin{array}{l}\text { Cap } 21 \text { - Equipollence } \\
\text { Cap } 22 \text { - Translations }\end{array}$ & \\
\hline & Cap VII - Simetrias Centrais & Cap 23 - Symétries centrales & \\
\hline & Cap VIII - Simetrias Paralelas & Cap 2 - Symétries parallèles & 3 \\
\hline & Cap IX - Grupos & Cap 24 - Groupes & 3 \\
\hline \multirow{9}{*}{ 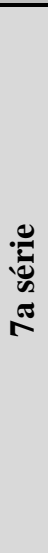 } & Cap I - Grupos e Ordem & $\begin{array}{l}\text { Cap } 1 \text { - Le Groupe } \Pi_{-}(0,+), \\
\text { Cap } 2 \text { - Le Groupe D_(0,),+, } \leq, \\
\text { Cap } 3 \text { - Graduations de la droite, } \\
\text { Cap } 4 \text { - Axiomed'Archimède, } \\
\text { Cap } 5 \text { - Sous-graduations de la droite }\end{array}$ & \multirow{9}{*}{ 交 } \\
\hline & Cap II - Os números Reais & Cap 6 - Nombres réels & \\
\hline & Cap III - O grupo ordenado dos Reais R,+ & Cap 7 - Le Groupe $R,+, \leq$ & \\
\hline & Cap IV - Teorema de Tales & Cap 8 - Théorème de Thalès & \\
\hline & Cap V - Homotetias & Cap 9 - Homothéties & \\
\hline & Cap VI - A multiplicação dos reais & Cap 10 - La multiplication des nombres réels & \\
\hline & Cap VII - Multiplicação escalar & Cap 11 - La multiplication scalaire & \\
\hline & Cap VIII - O corpo ordenado dos Reais & Cap 12 - Le champ ordonné des nombres réels & \\
\hline & Cap IX - O vetorial R,D_ $(0)+$, & \begin{tabular}{|c|} 
não há correspondência \\
\end{tabular} & \\
\hline
\end{tabular}


DOI: https://doi.org/10.20396/zet.v27i0.8654231

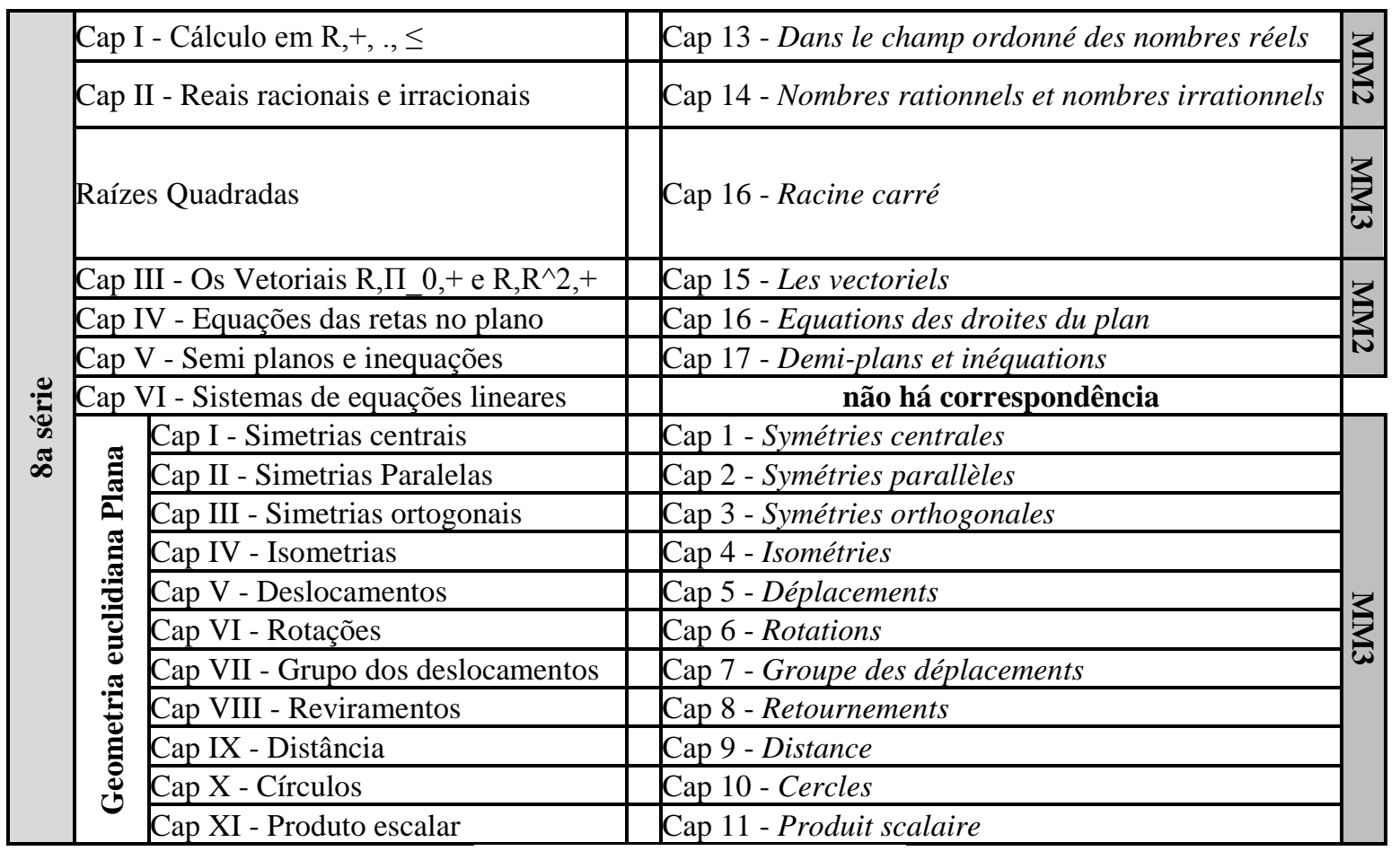

Fonte: Da Costa, 2014, p. 127-129

A primeira edição dos Apontamentos, de 1969, era distribuída em fascículos para os alunos ao longo do ano escolar; no decorrer do tempo, novas edições surgiram, já encadernadas e acrescidas de reflexões de Dom Ireneu oriundas dos anos em que se experimentava o material, e acrescidas de novas ideias pedagógicas por ele incorporadas.

Não foi encontrado nenhum exemplar dessa $1^{a}$ edição entre as fontes disponíveis, apenas o texto de seu Prefácio, que vem datado e reproduzido no exemplar da $2^{\mathrm{a}}$ edição que, por sua vez, data de 1975 .

Os prefácios que compõem os volumes da $2^{\mathrm{a}}$ edição (particularmente o volume II) apontam para algumas diferenças em relação à $1^{\text {a }}$ edição: qualidade das ilustrações, quantidade de exercícios, qualidade dos textos:

Esta segunda edição difere da primeira principalmente no fato de incorporar numerosos exercícios e (efeito da "queda do dólar...") não possuir ilustrações coloridas. Além disso, está consideravelmente aumentada na explicação de certos pontos excessivamente resumidos na primeira (Penna, 1975a, Prefácio).

Dom Ireneu, ironicamente, aponta a razão da necessidade de baixar a qualidade visual de seu trabalho: "a queda do dólar". De janeiro de 1970, logo após a data da $1^{a}$ edição teoricamente colorida, - para março de 1975 - quando é lançada a versão em preto e branco o dólar comercial brasileiro teve um aumento de 77,7 \% (DÓLAR COMERCIAL, 2018). Nota-se, daí, a limitação econômica com a qual Dom Ireneu esbarrou na produção de seus Apontamentos. Com certeza, a impossibilidade de se produzir um impresso colorido exigiu muitas manobras metodológicas. O resultado foi um impresso "seco", sem muita vida, pouco atrativo, todo em preto e branco. No entanto, isso não foi empecilho para que ele continuasse 
DOI: https://doi.org/10.20396/zet.v27i0.8654231

a ser utilizado no colégio até 2001, quando ainda se utilizavam as versões ditas "originais", em preto e branco.

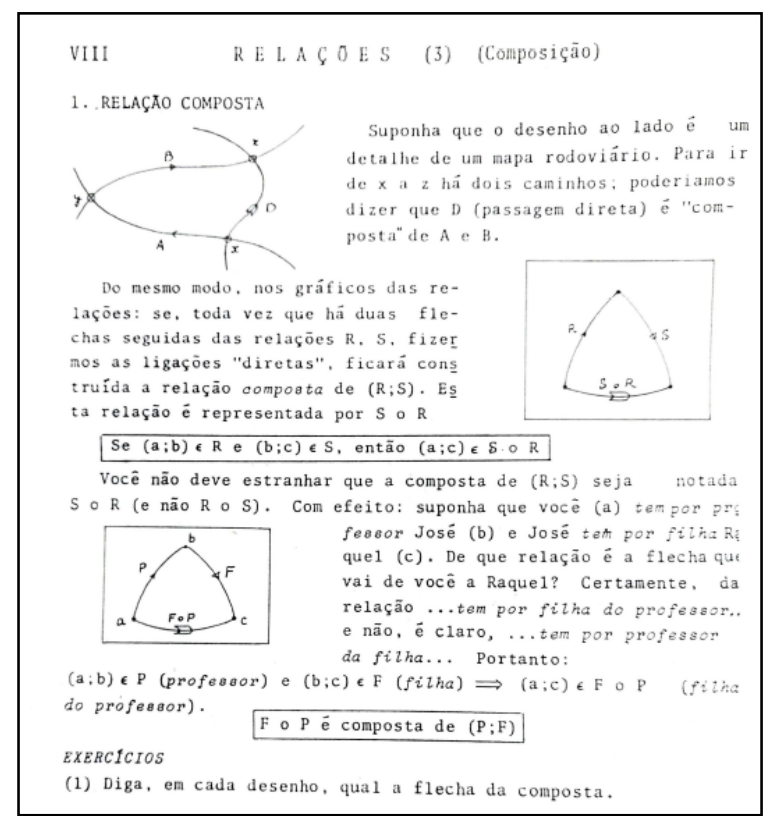

Figura 4 - Introdução do conteúdo Relações Compostas nos Apontamentos de Matemática de 1976. Os gráficos de flechas indicam as relações.

Fonte: Apontamentos de Matemática 1, p. 68. $3^{\mathrm{a}}$ ed. 1976.

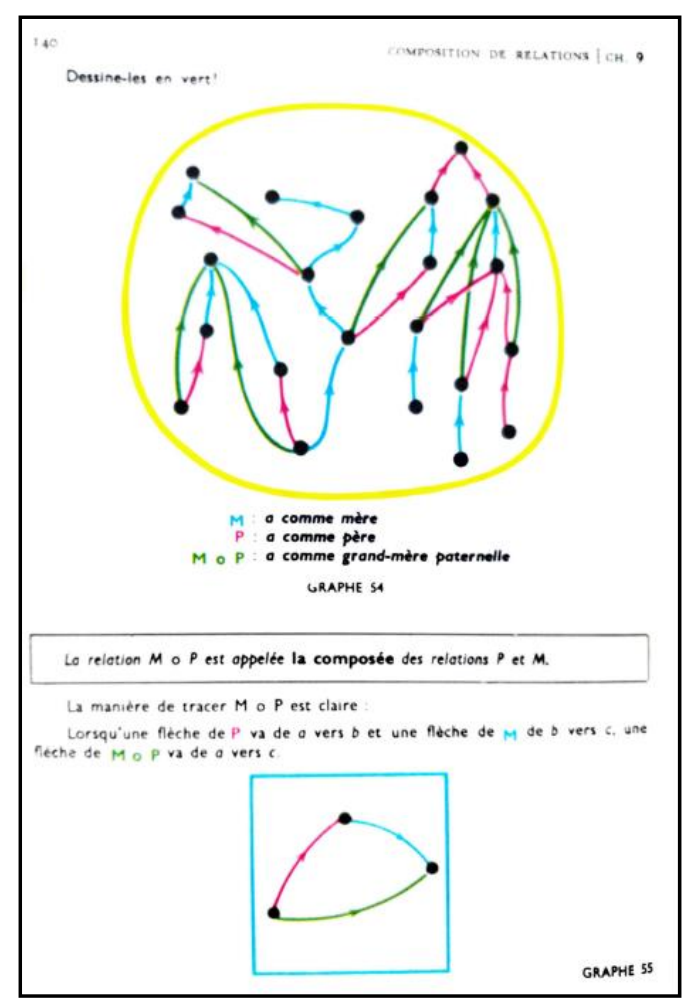

Figura 5 - Introdução do conteúdo Relações compostas no livro de Papy. Os diagramas com flechas indicam as relações.

Fonte: Papy, 1968a, p. 140. 
Para a $3^{\text {a }}$ edição, de 1976, Dom Ireneu dedicou-se ainda mais a melhorar as explicações dos conteúdos, ampliá-las e deixá-las mais claras. Aumentou novamente o número de exercícios e inseriu no corpo do texto, pela primeira vez, as aplicações dos conteúdos a situações matemáticas já estudadas em sala de aula, como o Jogo Lógico e os circuitos elétricos, que eram a aplicação de uma regra lógica ${ }^{16}$. Nota-se que essas aplicações são de autoria de Dom Ireneu, e que nada semelhante a isso encontra-se nos volumes de Papy. Diz Dom Ireneu no Prefácio da $3^{\text {a }}$ edição (Penna, 1976 - Prefácio):

Esta edição já é a $3^{a}$ formulação dos nossos APONTAMENTOS (1). Não difere muito das anteriores em conteúdo e método, nas suas linhas gerais mas, principalmente, no fato de ser mais explícita e menos resumida em certos pontos de detalhe, tornados assim, esperamos, mais claros e intuitivos. Há também maior abundância de exercícios (agora, mais de 600) e aplicações, inclusive aos circuitos elétricos, sempre explorados por nós no nosso ensino e até hoje não incorporados aos APONTAMENTOS. À Lógica foi concedido também um maior espaço, com apoio dos diagramas, circuitos, "Jogo Lógico", etc.

Dom Ireneu também faz algumas mudanças na metodologia, possibilitando ao aluno maior segurança no momento de formalizar um conceito. Lê-se no Prefácio que "um traço característico desta $3^{\mathrm{a}}$ edição é o recurso mais frequente à apresentação informal de um conceito, bem antes da sua apresentação oficial e já um tanto formalizada" (ibid).

\section{Considerações Finais}

O nascimento dos Apontamentos e a sobrevivência de suas posteriores edições conheceram dificuldades que não se relacionam a editores, distribuidores ou leitores. A editora era o próprio colégio, que também exercia a função de vendedor. O reitor do CSB, Dom Lourenço de Almeida Prado, deu pleno aval para Dom Ireneu prosseguir com o papysmo, e aceitou todas as consequências que daí adviriam. Dom Ireneu não precisou procurar um editor, tampouco um distribuidor. O colégio possuía sua própria reprografia, onde produziu todos os volumes dos Apontamentos, durante todo o tempo em que foi utilizado, e os exemplares eram vendidos aos alunos no próprio colégio. Quanto aos leitores, enquanto alunos, não tinham muita voz de aceitação ou de reprovação. Os Apontamentos representavam o conteúdo de matemática a ser estudado no colégio, e contra isso, os alunos leitores usuários na faixa de 11 a 14 anos - não tinham o que dizer: aceitava-se ou saía-se do colégio.

As dificuldades que Dom Ireneu precisou enfrentar ao decidir pelo papysmo já tinham sido por ele imaginadas desde o início. Em carta dirigida a Papy em 1967 (apud Penna, 1969), Dom Ireneu lhe diz que não lhe escapam as dificuldades de o seguir, quais sejam: os alunos não teriam livro-texto; os pais talvez iriam estranhar e não poderiam ajudar seus filhos; seria uma experiência única no Brasil e, sem dúvida, as críticas iam chover; culpariam o processo pelo mínimo insucesso; nenhum aluno novo poderia ser aceito depois de alguns meses escolares.

\footnotetext{
${ }^{16}$ Dom Ireneu fabricava circuitos elétricos com seus alunos, usando lâmpadas e pedaços de madeira.
} 
A primeira dificuldade apontada por Dom Ireneu é a falta do livro-texto. Entendemos, então, que os Apontamentos nasceram com essa função, suprir uma grave necessidade escolar. À medida que as experiências com o papysmo e com as primeiras edições dos impressos foram vistas como bem-sucedidas, novas edições foram elaboradas, com textos mais claros e com um número maior de exercícios:

Foi, porém, a qualidade dos resultados em média obtidos (sempre melhores que os de antigamente), a por vezes entusiástica receptividade dos alunos, a certeza enfim de estarmos com os melhores mestres no assunto, que nos forçaram quase a continuar o ensino no estilo por assim dizer revolucionário que lhe estamos imprimindo [...] (Penna, [1967 - 1970], p. 1-2).

As experiências satisfatórias que se sucederam, ano a ano, seguindo-se a proposta de Papy, impulsionaram as novas edições dos Apontamentos, reformuladas e melhoradas, até que, com a saída de Dom Ireneu do colégio no final de 1976, não se pensou mais em uma nova edição. Permaneceu em uso no CSB até 2001 a última edição dos Apontamentos, que data do início de 1976, cujo Prefácio retrata a alegria e entusiasmo do monge-professor com os sucessos das aulas. Reproduzimos aqui os dois últimos parágrafos do Prefácio do volume 1:

Quero dedicar esta edição, com carinho especial, à Quinta-Quinta-75, em cujo convívio alegre e estimulante surgiram muitas ideias para este trabalho, reflexo das agitadas aulas onde, tantas vezes, os golpes de gênio cruzavam-se no ar com as perguntas provocantes e ... as respostas precipitadas. À Quinta-Quinta jovial e séria, sempre disposta a aprender, sempre em trabalhos práticos onde a mais refinada teoria se via incorporada no esforço e na habilidade artesanal [...], na produção de circuitos e jogos lógicos, diagramas luminosos e cérebros mágicos, computadores de chaves comutadores e dispositivos de classificação!

Aos céticos e pessimistas, aos que decretam, citando ou não Piaget, que antes dos 14 anos não existe verdadeiro pensamento abstrato; que todo formalismo deve ser evitado (como se fosse possível!); que a índole axiomatizante da Matemática deve ser cuidadosamente camuflada, etc., etc., a nossa única resposta é um convite: venham ver a $5^{a}-5^{a}-75$, agora na $6^{\mathrm{a}}$ série, e depois leiam Piaget. Eles aprenderam, com 11 anos, tudo o que está nestes Apontamentos e mesmo mais. Um detalhe: trata-se de uma turma apenas normal (Penna, 1976, Prefácio - grifos do autor).

Observa-se, também, o nascimento de um autor a partir da constituição de um impresso didático que se inicia por uma tradução. Santana (2001), considerando exemplos na Literatura, reflete sobre a definição de autoria no contexto das traduções. Uma das problematizações levantada por ela no jogo que envolve autor, tradutor, ideias e direitos autorais é resumida a seguir:

Se [...] o direito de propriedade sobre as ideias não pode ser assegurado a ninguém, se a lei de direitos autorais reconhece que a autoria recai sobre a combinação de palavras escolhida por um autor para expressar uma ideia e se a tradução é orientada pela escolha de palavras que resultarão em uma outra forma de expressar uma determinada ideia - que, lembremo-nos, faz parte do patrimônio universal -, perguntar qual a diferença entre autor e tradutor perde qualquer sentido (Santana, 2001, p.95). 
DOI: https://doi.org/10.20396/zet.v27i0.8654231

Nessa perspectiva, podemos considerar os Apontamentos como um trabalho autoral, com marcas profundas das propostas de Papy, por natureza óbvia, mobilizadas por apropriações de Dom Ireneu Penna.

\section{Referências}

Da Costa, L.M.F. (2014). O movimento da Matemática Moderna no Brasil - o caso do Colégio de São Bento do Rio de Janeiro. Dissertação de Mestrado em Ensino de Matemática. Rio de Janeiro: Universidade Federal do Rio de Janeiro.

Darnton, R. O beijo de Lamourette. Editora Companhia das Letras, 2010.

Dassie, B.A., \& Da Costa, L.M.F. (2014). Dom Ireneu Penna: intelectual, monge, professor e educador matemático. Anais do $2^{\circ}$ Encontro Nacional de Pesquisa em História da Educação Matemática: fontes, temas, metodologias e teorias: a diversidade na escrita da história da educação matemática no Brasil. (pp.1186-1196). Bauru: Faculdade de Ciências, 2014.

Dassie, B.A., Da Costa, L.M.F. \& Carvalho, J.B.P.F. (2016). A trajetória de Dom Ireneu Penna e suas escolhas como educador matemático. Zetetiké, 23(44), 395-410.

De Bock, D. \& Vanpaemel, G. (2015). Modern mathematics at the 1959 OEEC Seminar at Royaumont. "Dig where you stand" 3. Proceedings of the Third International Conference on the History of Mathematics Education. (pp.151-168). Uppsala: Uppsala University.

Dolar Comercial Oficial. Informativo sobre o valor do dólar comercial a partir de 1970. Disponível em: <http://www.yahii.com.br/dolar.html>. Retirado em 18 de dezembro, 2018.

Miceli, S. (2001). Intelectuais à brasileira. São Paulo: Companhia das Letras.

Monteiro, P.M., \& Schwarz (2016), Uma edição crítica de Raízes do Brasil: o historiador lê a si mesmo, in Holanda, S.B. Raízes do Brasil. Edição Crítica. (pp. 11-26). São Paulo, Companhia das Letras.

Oliveira, F.D. (2010). Análise de textos didáticos de Matemática: um mapeamento e uma proposta metodológica fundada numa perspectiva hermenêutica. Bolema, 23(35B), 477 496.

Papy, G. (1967). Mathématique Moderne. (Vol.3). Bruxelas: Ed. Didier.

Papy, G. (1968a). Mathématique Moderne. (4a ed., Vol.1). Bruxelas: Ed. Didier.

Papy, G. (1968b). Mathématique Moderne. (Vol.2). Bruxelas: Ed. Didier. 
Santana, V.D. (2001). O tradutor como autor: transformação e sobre-vida do "original". Dissertação de Mestrado em Linguística Aplicada na Área de Tradução. Campinas, Universidade Estadual de Campinas. Retirado em 20 de janeiro, 2018, de: http://repositorio.unicamp.br/jspui/handle/REPOSIP/269588.

Soares, F.S. (2001). O movimento da matemática moderna no Brasil: avanço ou retrocesso. 2001. Dissertação de Mestrado em Matemática. Rio de Janeiro: Pontifícia Universidade Católica do Rio de Janeiro.

Valente, W.R. (2008). Osvaldo Sangiorgi e o Movimento da Matemática Moderna no Brasil. Revista Diálogo Educacional, 8(25), 583-613.

\section{Fontes}

Penna, I. [1967 - 1970]. Rio de Janeiro. [Circular para] Pais ou responsáveis por alunos da $1^{a}$ série ginasial do Colégio de São Bento. 3f. Tem por fim prestar contas e dar alguns esclarecimentos sobre a introdução do novo método de ensino de matemática no colégio.

Penna, I. (1968). Entrevista. Boletim da Associação de Pais e Mestres do Colégio de Aplicação.

Penna, I. (1969). Apresentação da tradução para o português do volume I do livro Mathématique Moderne de Papy. 4f.

Penna, I. (1976). Apontamentos de Matemática. (Vol.1) Rio de Janeiro.

Penna, I. (1975a). Apontamentos de Matemática. (Vol.2). Rio de Janeiro.

Penna, I. (1975b). Apontamentos de Matemática. (Vol.3). Rio de Janeiro.

Penna, I. (1975c). Apontamentos de Matemática. (Vol.4). Rio de Janeiro.

Ao Livro Técnico. (1969). [Carta para] Weimar Penna e José Paulo Quinhões Carneiro. 2f. Tem por fim confirmar o entendimento verbal sobre a tradução e adaptação do livro Mathématique Moderne (I) de Papy. 